\title{
Purificação do Álcool Isoamílico a partir do Óleo Fúsel
}

Tebas, S. O. G. ${ }^{1^{*}}$; Pereira, A. F. ${ }^{2}$; da Silva. P. H. A. ${ }^{3}$; Pinheiro, P. F. ${ }^{4}$; Pinheiro, C. A. ${ }^{4}$; Barañano, A. G. ${ }^{5}$

1 Graduando em Engenharia Química, Universidade Federal do Espirito Santo, Alegre, ES, Brasil. 2 Departamento de Química, Universidade Federal de Viçosa, Viçosa, MG, Brasil.

3 Departamento de Tecnologia de Alimentos, Universidade Federal de Viçosa, Viçosa, MG, Brasil. 4 Programa de Pós-Graduação em Agroquímica, Universidade Federal do Espírito Santo, Alegre, ES, Brasil. 5 Programa de Pós-Graduação em Engenharia Química, Universidade Federal do Espírito Santo, Alegre, ES, Brasil.

*e-mail: saulotebas@hotmail.com

\section{Resumo}

O óleo fúsel é um subproduto das usinas de etanol, em sua composição destaca-se a presença do álcool isoamílico (3-metilbutan-1-ol) como composto majoritário, sendo esse matéria-prima para a síntese de acetato de isoamila, um fixador de perfumes. No Brasil o óleo fúsel é vendido para as indústrias, frequentemente, na forma bruta, sendo que a purificação do mesmo pode ser importante na agregação do seu valor de mercado. Dessa forma, neste trabalho foi avaliado, a nível de laboratório, o rendimento, a umidade e densidade do óleo fúsel após filtração, destilação e secagem, bem como a sua composição química, após cada etapa, por cromatografia gasosa acoplada a detector de ionização de chamas (CGDIC).

\begin{abstract}
Fusel oil is an ethanol plant byproduct, in its composition stands out the isoamyl alcohol (3-methyl-butan-1ol) presence as the major compound, and this is raw material for isoamyl acetate synthesis, a perfum fixative. In Brazil, fusel oil is sold for industries often in raw form, and its purification can be important to aggregates market value. Thus, at laboratory scale this study had evaluated moisture and density of the fusel oil after filtration, distillation and drying, as well as its chemical composition after each step, by gas chromatography-ionization detector flames (GC-FID).
\end{abstract}

Keywords: fusel oil, purification, ethanol plant residue

\section{Introdução}

O óleo fúsel é um resíduo gerado nas usinas de etanol e apresenta em sua composição alcoóis superiores, sendo 0 álcool isoamílico (3-metilbutan-1-ol) o composto majoritário [1]; [2]. A produção do óleo fúsel ocorre a partir de reações de degradação de aminoácidos durante a fermentação das leveduras, para cada $1 \times 10^{3} \mathrm{~L}$ de etanol produzido, $2,5 \mathrm{~L}$ de óleo fúsel são gerados, sendo que sua produção aumenta com o incremento da produção do etanol [3].

A fração menos volátil e mais viscosa do processo de destilação do etanol constitui o óleo fúsel, que 
apresenta coloração amarelada, odor forte e temperatura de ebulição na faixa de 122 a $138{ }^{\circ} \mathrm{C}$ [4]. O óleo fúsel pode ser utilizado na indústria como solvente, na fabricação de cosméticos, medicamentos e sua principal aplicação é na obtenção do álcool isoamílico, sendo esse matéria-prima para a síntese de acetato de amila ou isoamila, um fixador para a perfumes, e também pode ser usado como agente purificador para ácido fosfórico [5].

Nas usinas de etanol o óleo fúsel, geralmente, não é aproveitado, sendo comercializado para outras empresas na forma bruta. Contudo, a purificação do óleo fúsel pode ser realizada por destilação e outros processos, o que poderia agregar valor ao subproduto. Dessa forma, este trabalho teve por objetivo purificar o óleo fúsel, em nível de laboratório e verificar a sua composição química por cromatografia gasosa com detector de chamas (CG-DIC).

\section{Materiais e Métodos}

Uma amostra de óleo fúsel $(5,00 \mathrm{~L})$ foi coletada em um tanque de armazenamento da Usina Jatiboca produtora de açúcar e álcool etílico, localizada em Urucânia - MG. Inicialmente, foram realizadas três filtrações (a vácuo) utilizando frações de $500 \mathrm{~g}$ do óleo fúsel, as massas dos filtrados foram aferidas. Após essa etapa, foram colocados $300 \mathrm{~g}$ do óleo fúsel em balão de fundo redondo que foi acoplado a um sistema de destilação fracionada e a temperatura ajustada para $130^{\circ} \mathrm{C}$ e o destilado foi coletado e a sua massa aferida.

O óleo fúsel destilado foi submetido a um processo de purificação de álcoois descrito por Perrin e Armarego [6], em um balão de fundo redondo de $500 \mathrm{~mL}$ foram adicionados 2,5 g de magnésio em pó, $0,25 \mathrm{~g}$ de iodo molecular e $50 \mathrm{~mL}$ de óleo fúsel destilado. A mistura ficou sob refluxo até o descoramento, passando da cor marrom para incolor (aproximadamente 1 hora). Subsequentemente, foram adicionados $190 \mathrm{~g}$ de óleo fúsel destilado, mantendo-se refluxo por mais $2 \mathrm{~h}$, em uma manta de aquecimento, em temperatura de 135 ${ }^{\circ} \mathrm{C}$. Após esse período, o óleo fúsel foi coletado, a sua massa foi aferida e o material foi armazenado sobre peneira molecular de $4 \AA$.

O teor de umidade do óleo fúsel purificado após cada etapa foi determinado de acordo com método de Karl Fischer, descritos pelo Instituto Adolfo Lutz (Zenebon et al., 2008), o equipamento utilizado foi o modelo HI 903 da marca Labor e para a obtenção da densidade foi usado o densímetro digital de bancada, modelo DMA 35 da marca Anton Paar.

O óleo fúsel foi analisado no cromatógrafo a gás modelo GC 17 A da Shimadzu, com detector de ionização de chama (DIC), usando uma coluna capilar de sílica fundida da marca Supelco PAG de $30 \mathrm{~m}$ de comprimento, 0,25 $\mathrm{mm}$ de diâmetro interno e espessura de filme de $0,20 \mu \mathrm{m}$. A temperatura do injetor usada foi de $180^{\circ} \mathrm{C}$ e a do detector $200^{\circ} \mathrm{C}$. A temperatura inicial da coluna foi de $35{ }^{\circ} \mathrm{C}$, permanecendo nesta por 5 minutos, sendo programada para aumentar a uma taxa de $10 \stackrel{\circ}{ } \mathrm{C} \min ^{-1}$ até $120 \stackrel{\circ}{ } \mathrm{C}$, permanecendo nessa temperatura por 10 minutos. Após esse período, a temperatura subiu a uma taxa de $10 \stackrel{\circ}{\circ} \min ^{-1}$ até 200 ${ }^{\circ} \mathrm{C}$ permanecendo nessa temperatura por 10 minutos [7].

Uma quantidade de $1 \mu \mathrm{L}$ de amostra foi injetada no modo split a uma razão de 1:10, o fluxo da coluna usado foi de $1 \mathrm{~mL} \min ^{-1}$. O gás de arraste utilizado foi o hélio em uma vazão de $30 \mathrm{~mL}^{\min ^{-1}}{ }^{-1}$, a vazão do ar sintético foi de $300 \mathrm{~mL} \mathrm{~min}^{-1}$ e a vazão do hidrogênio foi de $30 \mathrm{~mL} \mathrm{~min}^{-1}$. A quantificação dos componentes do óleo fúsel foi realizada pelo método da normalização por área.

\section{Resultados e Discussão}

Os rendimentos, a densidade e a umidade do óleo fúsel foram obtidos após as etapas de filtração, destilação e secagem, conforme mostrado na Tabela 1. Os rendimentos foram acima de $80 \%\left(\mathrm{~m} \mathrm{~m}^{-1}\right)$, devido a retirada das impurezas em cada etapa. $A$ densidade do álcool isoamílico puro é de $0,81 \mathrm{~g} \mathrm{~cm}^{-3}\left(20^{\circ} \mathrm{C}\right)$ a mesma encontrada para o óleo fúsel após a etapa de secagem. O teor de umidade do óleo fúsel após a 
filtração era de 18,34\%, após as etapas de destilação e de secagem foi para $7,24 \%$ e 1,00 , respectivamente.

Tabela 1: Rendimento e densidade do óleo fúsel obtido após as etapas de filtração, destilação e secagem.

\begin{tabular}{llll}
\hline $\begin{array}{l}\text { Óleo fúsel } \\
\text { (OF) }\end{array}$ & $\begin{array}{l}\text { Rendimento } \\
(\%)\end{array}$ & $\begin{array}{l}\text { Densidade } \\
(\mathbf{g} / \mathrm{mL})\end{array}$ & $\begin{array}{l}\text { Umidade } \\
(\%)\end{array}$ \\
\hline Filtrado & 80,97 & 0,84 & 18,34 \\
\hline Destilado & 80,09 & 0,84 & 7,24 \\
\hline Secado & 82,73 & 0,81 & 1,00 \\
\hline
\end{tabular}

Os dados de caracterização do óleo fúsel após as etapas de purificação foram apresentados na Tabela 2, esses estão de acordo com Pérez et al. [3] que encontraram no óleo fúsel, predominantemente, alcoóis, sendo que o composto majoritário determinado também foi o álcool isoamílico e foram encontrados ésteres em baixos teores.

Houve aumento da concentração de álcool isoamílico no óleo fúsel após as etapas de purificação, o que agrega valor ao subproduto, chegando até 96,56\% após a etapa de secagem.

Tabela 2: Caracterização química do Óleo Fúsel (OF) filtrado, destilado e secado.

\begin{tabular}{|c|c|c|c|c|}
\hline \multirow[t]{2}{*}{ T.R. (min.) } & \multirow[t]{2}{*}{ Composto } & \multicolumn{3}{|c|}{$(\%, \mathbf{C G})^{*}$} \\
\hline & & $\begin{array}{l}\text { OF } \\
\text { filtrado }\end{array}$ & $\begin{array}{l}\text { OF } \\
\text { destilado }\end{array}$ & $\begin{array}{l}\text { OF } \\
\text { secado }\end{array}$ \\
\hline 6,22 & Etanol & 14,58 & 9,36 & 0,05 \\
\hline 10,65 & Propan-1-ol & 0,08 & 0,11 & - \\
\hline 13,26 & Álcool isobutílico & 1,48 & 2,11 & 2,67 \\
\hline 13,94 & Álcool butílico & 0,02 & 0,02 & 0,03 \\
\hline 14,90 & Pentan-1-ol & 1,08 & 1,51 & 0,35 \\
\hline 17,27 & Álcool isoamílico & 80,76 & 86,07 & 96,56 \\
\hline 17,66 & Hexanoato de 3-metilbutila & 0,13 & 0,05 & 0,01 \\
\hline 18,85 & Octanoato de 3-metilbutila & 0,01 & 0,14 & 0,01 \\
\hline 19,08 & Decanoato de 3-metilbutila & 0,02 & 0,02 & 0,01 \\
\hline 19,35 & $\begin{array}{l}\text { Dodecanoato de } \\
\text { metilbutila }\end{array}$ & 0,02 & 0,01 & 0,01 \\
\hline 21,20 & NI & 0,34 & 0,04 & - \\
\hline 24,19 & $\mathrm{NI}$ & 0,21 & - & _- \\
\hline 26,83 & $\mathrm{NI}$ & 0,05 & - & - \\
\hline 27,20 & $\mathrm{NI}$ & 0,02 & - & - \\
\hline
\end{tabular}

O álcool isoamílico com alto grau de pureza apresenta alto valor comercial, podendo ser usado na síntese do butirato de isoamila, que apresenta sabor de banana e é muito utilizado na indústria de alimentos [8], na obtenção do acetato de isoamila que poder usado como flavorizante, devido apresentar odor agradável de frutas [9] e ainda como matéria-prima na fabricação de cosméticos, materiais de limpeza e como fixador de perfumes [10].

\section{Conclusões}

Após os processos sequenciais de filtração, destilação e secagem foi possível obter o álcool isoamílico com pureza de $96,56 \%$ a partir do óleo fúsel, sendo esse produto de grande aplicação industrial, sendo assim o referido resíduo de usina de etanol apresenta grande potencial a ser explorado.

\section{Agradecimentos}

Á Usina Jatiboca produtora de açúcar e álcool etílico, localizada em Urucânia - MG pelo fornecimento do óleo fúsel usado no trabalho.

\section{Referências}

[1] PATIL, A. G., KOOLWAL, S. M., \& BUTALA, H. D. Int. Sugar J., v. 104, p. 51-58, 2002.

[2] MOREIRA, R. F., NETTO, C. C., DE MARIA, C. A. Quim. Nova, v. 35, n. 9, p. 1819-1826, 2012.

[3] PÉREZ, E. R., CARDOSO, D. R., FRANCO, D. W. Quim. Nova, v. 24, n. 1, p. 10-12, 2001.

[4] DA MATA: Açúcar e Álcool. Óleo fusel. Valparaíso, SP, 2011. Disponível em: http://www.damata.ind.br/p.php?ID=24\&IDSessao=3 acesso em: 10 de setembro de 2016

[5] GÜVENÇ, A., KAPUCU, N., KAPUCU, H., AYDOĞAN, Ö., \& MEHMETOĞLU, Ü. Enzyme and microbial technology, v. 40, n. 4, p. 778-785, 2007.

[6] PERRIN, D. D.; ARMAREGO, W. L. F. Purification of Laboratory Chemicals, Oxford: Pergamon Press, 1998.

[7] PEREIRA, A. F.; Suplementação de nitrogênio sobre a fermentação alcoólica para produção de cachaça, cerveja e vinho. 96p. Dissertação (Mestrado em Ciência e Tecnologia de Alimentos); Programa de PósGraduação em Ciência e Tecnologia de Alimentos; Universidade Federal de Viçosa, Viçosa, 2007

[8] BANSODE, S. R., RATHOD, V. K. Process Biochemistry, v. 49, n. 8, p. 1297-1303, 2014.

[9] EISENMENGER, M. J., REYES-DE-CORCUERA, J. I. J. Mol. Catal. B: Enzym., v. 67, n. 1, p. 36-40, 2010.

[10] MCGINTY, D., LAPCZYNSKI, A., SCOGNAMIGLIO, J., LETIZIA, C. S., API, A. M. Food Chem. Toxicol., v. 48, S102-S109, 2010. 